\title{
I 007 Tolerance and safety of adenosine stress perfusion cardiovascular magnetic resonance imaging in patients with coronary artery disease
}

\author{
Theodoros D Karamitsos*1, Jayanth R Arnold ${ }^{1}$, Tammy J Pegg1, \\ Adrian SH Cheng ${ }^{1}$, William J van Gaal ${ }^{2}$, Jane M Francis ${ }^{1}$, Adrian Banning2, \\ Stefan Neubauer ${ }^{1}$ and Joseph B Selvanayagam ${ }^{1}$
}

Address: ${ }^{1}$ OCMR Unit, University of Oxford, Oxford, UK and ${ }^{2}$ Department of Cardiology, John Radcliffe Hospital, Oxford, UK

* Corresponding author

from I th Annual SCMR Scientific Sessions

Los Angeles, CA, USA. I-3 February 2008

Published: 22 October 2008

Journal of Cardiovascular Magnetic Resonance 2008, I0(SuppI I):AI32 doi:I0.II86/I532-429X-I0-SI-AI32

This abstract is available from: http://jcmr-online.com/content/I0/SI/AI32

(C) 2008 Karamitsos et al; licensee BioMed Central Ltd.

\section{Background}

Cardiac magnetic resonance (CMR) stress perfusion imaging with either adenosine or dipyridamole is increasingly used both in clinical and research practice. In nuclear Cardiology, the safety of adenosine stress has been confirmed in large-scale studies, although the data is more limited in the CMR setting. In theory, use of these stress agents in the CMR environment might be more risky due to the reduced robustness of ECG monitoring and the need for remote resuscitation in case of emergency, especially for patients with high likelihood of significant coronary artery disease (CAD). In this study, we sought to determine the safety and tolerability of adenosine stress CMR in patients with CAD.

\section{Methods}

We retrospectively examined all adenosine CMR perfusion scans performed in our centre between May 2003 and September 2007 in patients with suspected or documented CAD. These comprised both clinical and research scans, and were undertaken at either 1.5 Tesla (Sonata, Siemens Medical Solutions, Erlangen, Germany; $\mathrm{n}=160$ ) or 3 Tesla (Trio, Siemens Medical Solutions; $\mathrm{n}=152$ ). All subjects were screened for the presence of contraindications to adenosine (asthma, significant conduction abnormalities greater than first degree atrioventricular node [AV] block), and an ECG was performed prior to the scan. Information on safety and adverse events during and after adenosine infusion were routinely recorded, together with haemodynamic data. The dose of adenosine infused was $140 \mu \mathrm{g} / \mathrm{kg} / \mathrm{min}$ for all subjects. Safety precautions included the provision of resuscitation facilities with availability of aminophylline and glyceryl trinitrate. All scans were undertaken by staff familiar with and trained in the evacuation and resuscitation protocols of the unit. Significant CAD was defined angiographically as the presence of at least one stenosis of $>50 \%$ diameter.

\section{Results}

Data were collected from 312 consecutive subjects (mean age $62 \pm 11$ years, range $25-85$ years- 219 men). Of the 312 subjects, 280 had a coronary angiogram (the remaining 32 subjects were normal volunteers for research protocols). In total, 219 subjects (70\%) were found to have significant CAD: 92 patients with single-vessel disease, 69 with two-vessel disease and 58 with three-vessel disease, whereas 59 patients had no significant CAD. Per vessel, there were 16 left main lesions, 162 left anterior descending lesions, 104 left circumflex and 128 right coronary artery lesions. 309 subjects (99\%) successfully completed the infusion protocol (mean duration of infusion $231 \pm$ $48 \mathrm{sec}$, see Table 1 for haemodynamic data). Patients on beta-blockers showed a trend towards a diminished heart rate response compared with beta-blocker-naïve subjects 
Table I: Haemodynamic data at rest and during adenosine infusion.

\begin{tabular}{llll}
\hline & Rest & Adenosine stress & P-value \\
\hline Heart rate (beats/min) & $62 \pm 11$ & $81 \pm 13$ & 0.001 \\
Systolic Blood Pressure $(\mathrm{mmHg})$ & $132 \pm 18$ & $129 \pm 19$ & 0.001 \\
Diastolic Blood Pressure $(\mathrm{mmHg})$ & $76 \pm 11$ & $73 \pm 12$ & 0.001 \\
Rate-Pressure Product $(\mathrm{mmHg} \times$ beats $/ \mathrm{min})$ & $8190 \pm 2022$ & $10451 \pm 2554$ & 0.001 \\
\hline
\end{tabular}

Data are mean values \pm standard deviations

( $19 \pm 9$ vs $21 \pm 9$ beats/min, $\mathrm{p}=0.05)$. Importantly, there were no deaths, myocardial infarctions, or episodes of bronchospasm or pulmonary oedema. Transient AV node block ( $2^{\text {nd }}$ or $3^{\text {rd }}$ degree $)$ occurred in 25 patients $(8 \%)$. There were no sustained episodes of advanced AV block. Chest pain was frequently reported (165 subjects - 53\%) but sublingual nitrate administration was needed in only 4 subjects (1\%) after the infusion was stopped. Several patients reported breathlessness (129 subjects $-41 \%$ ) or other vasodilator side-effects such as flushing, headache, dizziness (126 subjects - 40\%). However, all these symptoms resolved with termination of the infusion and no aminophylline reversal was required.

\section{Conclusion}

In a large series, the use of intravenous adenosine in CMR perfusion imaging is safe and well tolerated in patients with even severe CAD. If a careful screening policy for contraindications to adenosine is followed, serious adverse events in the CMR scanner are relatively rare and most symptoms resolve following termination of the infusion without the need for aminophylline.
Publish with Bio Med Central and every scientist can read your work free of charge

"BioMed Central will be the most significant development for disseminating the results of biomedical research in our lifetime. "

Sir Paul Nurse, Cancer Research UK

Your research papers will be:

- available free of charge to the entire biomedical community

- peer reviewed and published immediately upon acceptance

- cited in PubMed and archived on PubMed Central

- yours - you keep the copyright

Submit your manuscript here:

http://www.biomedcentral.com/info/publishing_adv.asp
BioMedcentral 